\title{
Bronce y sueños, los gitanos. Nomadismo, identidades por exclusión y otredad negativa en Jorge Nedich y Josef Koudelka
}

\section{Ruiz, Laura [ver currículum del autor, docente de la Facultad de Diseño y Comunicación]}

Resumen:

Este trabajo se propone examinar los modos de contar o de representar en los que la palabra y la imagen ponen en escena características del transcurrir en el mundo del pueblo Rrom ("gitano"): nomadismo, persecución, marginación y la propia obstinación por permanecer en un presente perpetuo. Enfocándose en la novela El aliento negro de los romaníes, en el texto de no-ficción El pueblo rebelde. Crónica de la historia gitana, ambos del escritor rromargentino Jorge Nedich, y en la fotografía del checo-francés Josef Koudelka (en Gypsies), el artículo explora la aporía de presentar simbólicamente un pueblo que, a

Cuadernos del Centro de Estudios de Diseño y Comunicación № 61

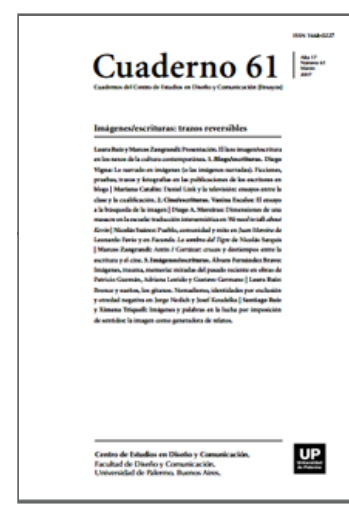

descargar PDF ver índice de la publicación

Ver todos los libros de la publicación

compartir en Facebook Argentina | 176 páginas

Imágenes/escrituras:

trazos reversibles

Año XVII, Marzo 2017, Buenos Aires,

Argentinal176 páginas

pesar de ser ágrafo, ha transitado la literatura y el arte como un otro exótico, estetizado o estereotipado por el discurso condescendiente de las hegemonías nacionalistas ilustradas.

Palabras clave:

nomadismo - otredad - identidad - literatura - fotografía - gitanos.

( ${ }^{*}$ ) Doctora en Letras egresada de University of Florida (Estados Unidos), Magister in Spanish por University of Michigan (Estados Unidos) y Licenciada en Letras por la Universidad Nacional de Comahue. Ejerció docencia en universidades de los Estados Unidos, como así también en Cuernavaca, México, y en Santander, España y en universidades nacionales privadas (Universidad de Palermo) y públicas (Universidad Nacional del Comahue, Instituto del Servicio Exterior de la Nación, ISEN). 
Nuestra era [...es] un símbolo siempre y constantemente [de] la no documentada agitación de los exiliados sin tierra ni hogar, de los inmigrantes, de las poblaciones itinerantes o cautivas para quienes todavía no existe documento ni expresión adecuada que refleje la situación que atraviesan [...] Creo firmemente que el humanismo debe ahondar en los silencios, en el mundo de la memoria, de los grupos mónadas que apenas consiguen sobrevivir, en los lugares de la exclusión y la invisibidilidad, en ese tipo de testimonios que no aparecen en los informes.

(Edward Said) Posiblemente sean las (re)interpretaciones de las teorías sobre el nomadismo desarrolladas por Giles Deleuze y Félix Guattari (1988) las que han promocionado cierta fascinación por la figura del nómada como "un transgresor romántico, un rebelde heroico y solitario" (Arditi, 2000, p. 118) que se niega a someterse a cualquier orden social establecido. Esta imagen del nómada ha sido empleada en el discurso intelectual como reconocimiento a la diversidad y a una existencia pluralista (Arditi, 2000) y se la ha ubicado en un deambular conceptual y cultural que viene a cuestionar al pensador perezoso de las culturas centralizadas y estáticas del mundo occidental contemporáneo (Denson, 2000).

La figura del nómada que existe en el pensamiento contemporáneo influyó en el campo intelectual, donde se insertó como modos discursivos (Deleuze y Guattari; Denson) y, también, se incorporó en las maneras y condiciones de alguna producción artística. La corporalidad material por antonomasia -aunque mucho menos romántica- de esta figura tiene su correlato en el pueblo rrom/“gitano"1, que ha transitado la historia, la literatura y el arte de occidente en tanto topos, así como ha errado por territorios geográficos reclamando, únicamente, derecho de paso (Unión Romaní). El análisis que aquí se propone comienza, en consecuencia, con una revisión de la dislocación de estas minorías en tránsito en una cartografía demarcada desde la retícula conceptual de "identidades por exclusión" y desde la conformación de una "otredad negativa" (Feierstein). Se examinan, luego, rasgos distintivos de los textos literarios (la elección de estrategias específicas de narración, su errancia entre géneros) y el poder de ciertos textos visuales que constelan relatos silenciados.

Ese otro expulsado que, desde un afuera (textual, social), interpela la necesidad de (re)posicionar los estudios humanísticos, pero sin convertirlo en objeto de investigación, tal como fue cristalizado en objeto exótico a partir el siglo XVII.

Quedarse afuera: los modos de construcción de identidad

En una diáspora que ha durado muchos siglos, el pueblo rrom se mantiene unido por un origen común, cuyo único testimonio es su lengua. A pesar de no tener registro escrito y de que su idioma se divide en tantos dialectos como grupos rromaníes existen en el mundo, los estudios lingüísticos lograron aclarar, en parte, la oscuridad de su proveniencia2. Su circunstancia histórica de exclusión, marginación, invisibilización y hasta de víctimas de genocidio se vincula, directamente, con los procesos de construcción de los Estados-nación, en términos de una hegemonía excluyente y de la construcción de una otredad negativa.

Afirman Gilles Deleuze y Félix Guattari (1988) que la historia se escribe desde el punto de vista de los sedentarios, en nombre de un aparato de Estado unitario que nunca ha tenido en cuenta el afuera; un Estado que busca ser la imagen interiorizada de un orden del mundo y que pretende afincar a los individuos en él ( $p$. 27). Del mismo modo, la figura del rrom/gitano3 que vive afuera de la historia, excluido de los Estados-nación, 
rompe la ilusión de progresión a través del tiempo histórico e incorpora, también, una atemporalidad a la narrativa (Trumpener, 1992, p. 869).

Los Estados europeos y las leyes: identidad por exclusión

Los Estados-nación modernos se construyeron a partir de procesos de negación de algunas de las identidades que son, también, parte de ese colectivo habitante del territorio demarcado como "nacional". Daniel Feierstein ha postulado que el aparato estatal, al constituirse, lo hizo a partir del concepto de "identidad por exclusión". Esto es, para que la identidad de un estado se constituya como tal, requiere seleccionar una de sus características y supeditar toda la identidad a ese elemento elegido, negando los demás elementos o "integrándolos" al hegemónico. Es decir que, en esta lógica de modelos de identidad, para formar parte de un estado, la característica elegida barre con cualquiera otra posible (Feierstein, 2005, p. 26).

Este modelo de "identidad por exclusión" percibe como problemáticos, para el propio Estado, a los grupos que se presentan heterogéneos o complejos. El Estado-nación moderno necesita reducir la identidad a uno solo de sus elementos, por eso persigue o coacciona de distintas maneras a quienes poseen y reafirman identidades múltiples. La persecución o el odio responden a lo que tales grupos identitarios son, es decir, se persigue a lo que se conoce y no a lo desconocido. El rechazo se ejerce, más bien, sobre la manera en que esos extraños insisten en ser lo que son y sobre la persistencia que tienen en mantener una identidad cultural que nunca buscaron deviniera en territorial nacional, como es el caso del pueblo rrom4. En definitiva, se ejerce contra su tendencia a la "inasimilibilidad" (Bhabha, 2013).

En el mismo sentido, para Feierstein, el concepto de "integración" ha sido el modelo básico por el que ciertas identidades han sido olvidadas, negadas o perseguidas (2005, p. 25-28).

En la modernidad, la identidad nacional se articuló, en la mayoría de los casos, bajo un componente excluyente modelado como una identidad "occidental y cristiana" y, en otros pocos casos, en un sentido laicizante, o incluso agnóstico y racista, como lo fue el nuevo hombre del Reich alemán (Feierstein, 2007, p. 396).

Se considera al Estado español como uno de los primeros en constituirse de acuerdo a la concepción moderna. Según Feierstein (2005, p. 26), en este "proto-estado" (por lo temprano de su surgimiento) radica la genealogía de un modo de construir identidades, que inaugura el concepto de "identidad por exclusión" y establece un prototipo que luego va a recuperar el conjunto de los Estados modernos.

Hacia el siglo XV, en el territorio que después se constituirá como perteneciente al Estado español, convivía una enorme variedad cultural e identitaria, compuesta por judíos, cristianos, rrom, musulmanes. Este proto-estado va a implementar la lógica del primer Estado-nación moderno confesional, noción de "una identidad estatal confesional excluyente" (Feierstein, 2005, p. 27) lo cual implicará la negación de la multiplicidad identitaria, que había existido previamente en ese territorio. Se explica, entonces, la persecución y expulsión de judíos, musulmanes y rrom en la época de los Reyes Católicos a partir de esta lógica de modelos de identidad que borran cualquier identidad-otra. 
Este modo de constituir la representación de la identidad propia determina las "identidades por exclusión” y necesita negar la multiplicidad concentrando toda esa identidad -como se dijo- en uno solo de sus componentes. La identidad por exclusión exige, como antítesis, la configuración de "otredades negativas" (Feierstein, 2007, p. 395).

En sus estudios sobre genocidio, Feierstein entiende que éste es una práctica social y, en tanto proceso, se desarrolla en el tiempo. Además, requiere de un momento conceptual inicial que el autor llamó "la construcción de otredades negativas". No resulta posible, afirma, desarrollar el conjunto de prácticas sociales que implica un genocidio sin haber delimitado, previamente, modelos de construcción de identidad y de alteridad, representaciones simbólicas que son modos en que los individuos se perciben a sí mismos; representaciones que son, también, maneras de construir lo que se ubica en el lugar de la alteridad y, simultáneamente, una operatoria de negativización de ese otro rechazado. Las diversas experiencias históricas genocidas fueron posibles por el proceso de deshumanización del otro diferente para quebrar su dignidad como ser humano.

Para poder implementar los procesos de deshumanización, el requisito ineludible es deshacerse de cualquier rasgo de alteridad que se encuentre presente en cada uno de los individuos que componen el conjunto de la identidad del Estado-nación. No es posible eliminar a quien se considera parte de lo propio, por lo cual resulta más sencillo deshacerse de lo diferente cuando se lo ha ajenizado. Este mecanismo es lo que Zygmunt Bauman llamó “adiaforización”: la indiferencia hacia el otro que produce su extrañeza (Feierstein, 2007, p. 396)5.

Una vez que lo otro se incorpora como existencia negativa, se busca limitar sus espacios, regular sus movimientos; así, se reordena el territorio por el que se le permite transitar: hay zonas prohibidas y zonas permitidas (Feierstein, 2000, p. 41). En ese sentido, la consolidación de los Estados creó grupos de individuos que fueron política y culturalmente excluidos. Desde otra perspectiva, para Benedict Anderson, la nación imaginada se concibió a partir del principio excluyente de una lengua común, que se unificó con el impacto del capitalismo impreso. La creación de un lenguaje único permitió a una parte de la población identificarse entre sí y dejar afuera a otra parte. Vista como una comunidad imaginada, la nación se presenta, entonces, simultáneamente abierta y cerrada (Anderson, 1993, p. 205).

Sin embargo, el rechazo, el hostigamiento y los intentos de exterminio del pueblo rrom empezaron muchos siglos antes de la conformación de los Estados modernos: desde los inicios de su nomadismo. Se sostiene que, alrededor del año 1000, grupos no uniformes abandonaron su tierra en el norte de la India en éxodo hacia el oeste. No se conocen los motivos, pero se conjetura que era una cultura organizada y avanzada para la época y que, forzados por el sistema de castas, los rrom se hicieron nómadas en su territorio de origen.

Probablemente, las invasiones arias y las posteriores invasiones musulmanas provocaron su dispersión por el mundo en una doble diáspora (Grande, 1984, p. 28).

Gracias a los estudios lingüísticos, en el siglo XVII se pudo establecer que las primeras migraciones salieron del norte de India y se logró reconstruir su derrotero. Para ello, se tuvieron en cuenta los préstamos de un léxico básico a los que fueron permeables y las construcciones gramaticales similares a otras lenguas con las que tuvieron contacto en su peregrinar. Se pudo establecer, también, que nunca permanecieron demasiado tiempo en un lugar como para resultar asimilados (Soravia, 1984; de Vaux de Foletier F., 1984). La organización Unión 
Romaní coincide en que los pobladores de la India emprendieron el éxodo hacia el oeste debido a la invasión del Islam en el siglo IX y que, en el siglo XIII, la invasión de los ejércitos mongoles provocó una segunda migración.

Unos llegaron a Europa a principios del siglo XIV, desde Asia Menor, por Creta y el Peloponeso y siguieron su dispersión hacia el Oeste y el Norte. A fines del siglo XIV se habían establecido en los Balcanes y en la zona del Danubio. Eran zapateros y herreros y los gobernantes los incorporaron al orden social y económico, permitiéndoles trabajar con imposición de impuestos o, en su defecto, haciéndolos sirvientes (Guy, 1975).

Los que llegaron a Europa occidental tienen una historia diferente. En 1417 un grupo importante apareció en Hungría. Después de viajar hacia el oeste, cruzaron Eslovaquia y Bohemia y allí se dividieron en grupos que luego llegaron a Alemania, Suiza, Italia, Francia y al norte de España. Está documentado que, en 1418, Ilegaron a Hungría y Alemania, donde el emperador Segismundo accedió a concederles cartas de protección.

Tres años después, llegaron a los Países Bajos, provocando la curiosidad entre los habitantes locales. Como allí estaban en tierras del emperador Segismundo, las cartas de protección imperiales que exhibían no tenían valor. Estos grupos comprendieron, entonces, que si querían seguir transitando libremente por el mundo cristiano debían conseguir una salvaguardia de carácter universal: la protección papal (de Vaux de Foletier, 1984).

En 1422, un grupo pasó por Bolonia y Forli declarando que iban a ver al Papa, aunque no hay registro de esto ni en los archivos del Vaticano ni en ninguna crónica. Pero a su regreso, relataban cómo habían sido recibidos por el Papa y presentaban cartas suyas de cuya autenticidad se duda. Reales o no, estas cartas papales aseguraron que los grupos nómadas fueran bien recibidos y se les permitió circular por donde quisieran.

La opacidad del origen de los rrom se alimenta con las propias intervenciones en la narración de su historia al incorporar relatos extraordinarios y misteriosos a la misma (Unión Romaní). Ellos cuentan que cuando partieron de Egipto eran paganos y que para ganarse la confianza de las autoridades espirituales o temporales, se convirtieron al cristianismo, nuevamente en idólatras y otra vez al cristianismo, por presión de los monarcas. Cuando llegaron a París por primera vez, atrajeron a una multitud de curiosos y, también, fueron causa de escándalos. Se comentaba que, mientras las mujeres leían las líneas de la mano, desaparecían las bolsas de dinero, por lo que estos visitantes fueron obligados a marcharse.

Llegaron a la Península Ibérica al principio del siglo XV. En enero de 1425, Alfonso V ordenó a las autoridades de la Corona de Aragón que permitiera a Juan de Egipto Menor y a las personas que venían a sus órdenes, el tránsito por el reino durante tres meses a partir de la fecha de su firma. El salvoconducto -fechado en Zaragoza y conservado en el Archivo de la Corona de Aragón- constituye la prueba documental más antigua de que disponen las investigaciones sobre la llegada de los rrom a tierra española. Cuatro meses más tarde, en mayo de ese año, el mismo Alfonso $V$ extiende otro salvoconducto a favor del rrom Thomas de Egipto y los suyos, en el que les autoriza a transitar y a habitar en el reino (Grande, 1984).

Durante años se siguieron extendiendo este tipo de salvoconductos reales a favor de rrom "nobles" como "Andrés, duque de Egipto Menor" y Pedro, Martín y Tomás: "condes de Egipto" a quienes se sumaron otros grupos migrantes que aseguraban estar peregrinando hacia Roma o hacia Santiago de Compostela. Esta justificación estimulaba la benevolencia de los poderosos y la tolerancia de los pobladores locales. Vivían de la limosna, de hacer magia, de adivinar la suerte, de comprar y vender caballos y también de robos menores 
(Grande, 1984, p. 30). En realidad, los títulos nobiliarios eran falsificados o comprados y las peregrinaciones a Roma o a Compostela no eran sino embelecos para lograr beneplácito en las tierras de la Europa cristiana (Grande, 1984, p. 29). En su peregrinación a la Santa Sede, afirmaban que iban en busca de la bendición papal, sin embargo, la verdadera finalidad era la entrega de una carta que aseveraba la inocencia del pueblo rrom en hechos vinculados a la muerte de Cristo, por los que eran maltratados (Nedich, 2010, p. 137).

Los rrom nunca llegaron a Roma y la Iglesia católica promovió su persecución instruyendo al poder político y alertando sobre la peligrosidad de sus costumbres. Además, hizo circular esa versión que los culpaba de haber fabricado los clavos para la crucifixión de Cristo a cambio de monedas de oro (Nedich, 2010, p. 137-38), por lo cual quedaron condenados a marchar sin rumbo por el mundo. Esta exégesis fue utilizada como justificación para posteriores persecuciones y muertes6.

Para defenderse de esta historia que inventó el poder de la Iglesia católica, el pueblo rrom le cambió el final, no solo para liberarse de la culpa sino también para justificar su idiosincrasia nómada: "los clavos ya estaban allí esperando a Cristosu cuando nosotros llegamos.

Sucedió que el ladrón que robó uno de los cuatro clavos fue uno de los nuestros; por eso desde aquel día, bendecidos por Cristosu, podemos andar libremente por el mundo" (Nedich, 2010, pp. 138-139).

Así, los primeros relatos sobre su arribo a Europa occidental sugieren que la curiosidad y la simpatía que despertaron en un principio derivaron en sospecha y hostilidad y pronto su situación pasó de huéspedes protegidos a perseguidos fuera de la ley.

El aparato legal

En los primeros cien años desde la llegada de los rrom a Europa Occidental se aprobaron leyes para su expulsión y algunas llegaron a incluir la pena de muerte (Guy, 1975). En Europa Oriental, la primera legislación contra este pueblo tuvo como disparador una serie de incendios provocados en Praga, en el año 1541. Sin ninguna justificación, los rrom fueron acusados de actuar pagados por los turcos invasores. De aquí en adelante, la legislación para expulsarlos de la actual República Checa fue sostenida. Esto derivó en graves intentos de exterminarlos como grupo durante los años posteriores a la Guerra de los Treinta Años (1618-1648). Muchos rrom fueron mutilados y, como advertencia, se colgaron partes de sus cuerpos de árboles, en la frontera. En Eslovaquia se prohibió el nomadismo y se pusieron carteles que prometían una amnistía para aquellos que se "asentaran" dentro de las tres semanas de su paso por la frontera (Guy, 1975).

La legislación relativa a los rrom, desde sus comienzos hasta la actualidad, se manifiesta como una práctica arbitraria y se ha ido conformando bajo el concepto de "identidad por exclusión"; aunque a comienzos del siglo XXI los hostigamientos dejan de ser básicamente judiciales y comienzan a ser persecuciones en el terreno social.

El surgimiento de los nacionalismos europeos que, entre otras características, identificó a los pueblos en su relación histórica con el territorio, redefinió la sociedad civil para evitar que este grupo formara parte de la nación o de que fundara una nación distinta y propia (Trumpener, 1992; San Román, 1985). 
En Gran Bretaña, un cuerpo policial y jurídico trabajó sistemáticamente hasta bien avanzado el siglo XVIII para "erradicar a los gitanos del país por medio de la prohibición y la ejecución". En 1780 se hizo un ahorcamiento colectivo y público para que sirviera como marca simbólica que señalara el fin de la excesiva persecución severa (Trumpener, 1992, p. 863). Los rrom itinerantes tenían obligación de buscar un amo y de establecerse, así muchos se convirtieron en esclavos, situación que duró hasta mediados del siglo XIX7.

En pleno siglo XX, el 3 de junio de 1960, Francia promulgó una ley que establecía la creación de documentos de circulación: consistían en una libreta especial para quienes ejercían regularmente una actividad profesional y en un documento de tránsito para los que no tuvieran una actividad comercial, artesanal o industrial regular y que no justificaran ingresos suficientes. Este documento necesitaba un visado mensual, entre otras restricciones.

El establecimiento de viviendas móviles que, en principio, se autorizaba libremente, en realidad estaba rígidamente regulado. Para el modo de vida sedentario, este cuerpo de legislaciones produjo como negativo el carácter específico de nómada, cuya identidad solo se tenía en cuenta si se constituía como problemática.

También en Bélgica, bajo la noción de "nacionalidad indeterminada" vigente hasta ahora, los individuos pierden derechos fundamentales. En Alemania, los rrom todavía no consiguen reconocimiento oficial ni la indemnización que la ley establece como reparación a las víctimas del nazismo. Tampoco Estados Unidos los ha incluido en el Memorial del Holocausto.

El preludio del Holocausto -en el que se calcula que el setenta o el ochenta por ciento de la población rrom fue aniquilada al terminar la Segunda Guerra Mundial (Unión Romaní)- empezó con el dictado de nuevas leyes que prohibían el nomadismo, con pogroms en Eslovaquia, en el año 1928, en los que se mataron, incluso, a niños pequeños. Estos asaltos encontraron su justificación en la prensa popular: El caso puede caracterizarse como una revuelta de ciudadanos contra el estilo de vida de los gitanos (...) el elemento gitano, como lo es hoy, es realmente una úlcera en el cuerpo de nuestra vida social que debe ser curado en una forma radical.

(Guy, 1975, traducción propia) Al año siguiente se prohibió a los rrom desplazarse dentro del país sin autorización de la policía, y los mayores de dieciséis años que no podían justificar un empleo eran sometidos a trabajo forzado en un establecimiento de reeducación, por un máximo de dos años (Novitch, 1984, p. 23).

En los sistemas no-capitalistas

Cuando el socialismo llegó al poder en Europa Oriental, se intentó resolver el "problema social" de los rrom por medio de la sedentarización compulsiva, aunque se les ofrecían facilidades para que conservaran su patrimonio cultural (Charlemagne, 1984, p. 11). En la ex Checoslovaquia, durante la posguerra, atraídos por la promesa del gobierno comunista de que no se tolerarían las prácticas discriminatorias, miles de familias rrom dejaron los asentamientos en los que habían vivido virtualmente como prisioneros y fueron a buscar trabajo en las zonas industriales. Fue la primera vez en la historia que los rrom entraron en el mercado laboral en grandes números, como trabajadores sin calificación, en fábricas o en la construcción. Mientras los gobiernos aprobaron a desgano la migración masiva como "una respuesta positiva para sus nuevas oportunidades", se advirtió que tanto en ciudades, asentamientos o en los caminos los gitanos aún vivían una vida segregada, en parte buscada por ellos, en parte impuesta (Guy, 1975). Hay que tener en cuenta que la retórica tradicional de los partidos de izquierda parecía haber excluido completamente la situación de los rrom, ya que eran vistos como migrantes 
"no- trabajadores" que vivían fuera de las luchas económicas, de las políticas y de las de clase (Trumpener, 1992, p. 873).

Nuevo mundo, viejos comportamientos

Entre el siglo XV y XVIII había grupos rrom distribuidos por casi todos los países de Europa y, a principios del siglo XVI, comenzaron los casos de deportaciones de Portugal y España hacia las colonias de África y de América. Se afirma8 que algunos fueron traídos por Pedro de Mendoza en 1536 y que su situación fue similar al éxodo original de la India y al subsecuente nomadismo en Europa: como consecuencia del hostigamiento racista y discriminatorio.

Tiempo después, muchas familias decidieron embarcarse hacia el Nuevo Mundo, aun cuando ya se conocía que aquí también eran perseguidos. Por ejemplo, la legislación de Indias ordenó la captura y subsecuente deportación de todos los grupos itinerantes descubiertos dentro del continente americano (Bernal, p. 14).

En "Los Rrom en las Américas", Jorge Bernal subraya que la documentación sobre este pueblo en el Nuevo Mundo es prácticamente inexistente y que la información sólo se obtiene de los ancianos de la comunidad y de otros miembros ubicados en los distintos países de América (Bernal, 2014). Actualmente, hay grupos que hablan rromaní y que conservan sus tradiciones en todo el territorio americano, desde Alaska hasta Tierra del Fuego, además de Europa, Australia, África y algunos sitios de Asia.

Las primeras migraciones importantes hacia Argentina, Brasil, Colombia, Perú, Ecuador y Cuba se registran a principios del siglo XX, entre 1900 y 1920. Las condiciones de vida fueron similares en todo el continente con el consecuente surgimiento de leyes y decretos prohibiendo la itinerancia en todos los países que habitaban. En Paraguay no existe población rrom porque el gobierno militar de Alfredo Stroessner (1954-1989) le prohibió la entrada al país (Bernal, Asociación Identidad Cultural Romaní en Argentina AICRA, 2014).

En el siglo XX, en Argentina, se sucede una serie de prohibiciones con leyes del mismo tenor que las de Europa. Por ejemplo, durante la primera presidencia de Juan D. Perón (1946-1952) se prohibió la instalación de carpas en todo el territorio nacional. Para dar cumplimiento, anónimamente se incendiaron los campamentos rrom. Nunca se supo cuántos muertos y heridos dejaron estos ataques. También, en la década de 1960, el gobierno militar, encabezado por el general Juan Carlos Onganía, prohibió el atuendo característico de las mujeres rrom, así como, en la década siguiente, bajo la hipótesis de conflicto con Chile y amparándose en una ley de emergencia, se les expropiaron las camionetas a los rrom residentes en el sur del país, vehículos que jamás fueron restituidos a sus dueños.

Durante el gobierno de Raúl Alfonsín (1983-1989) se prohibió el tránsito de pueblos nómadas por la provincia de Río Negro, pero la presión de la prensa internacional obligó al gobierno provincial a revisar esa ley (Nedich, 2010, p. 34)9.

Todo intento de "solucionar" el problema rrom, en cualquier lugar del mundo, con cualquier tipo de gobierno, tuvo que ver con las tendencias de asimilación y con las políticas de sedentarización casi siempre compulsivas, que se debatieron entre dos opciones: la pérdida de la identidad rrom y la marginación de tales grupos en tránsito. Si 
se sedentarizan, las condiciones de vida son deplorables y terminan conformándose barrios marginales "de gitanos" en los anillos externos de las ciudades.

En las políticas asimilacionistas, cuando las administraciones gubernamentales los empujan a reservas agrupando unas familias con otras (San Román, 1985), se transgreden normas de derecho milenarias que muchos rrom aún no están dispuestos a olvidar y, además, se los obliga al confinamiento, a un destino de servicio militar o laboral, en todos los casos. La costumbre de los rrom era viajar en grupos formados por una familia extensa de padres, hijos casados, nueras y nietos con un escrupuloso código de derecho al momento de trazar sus territorios. Los barrios donde viven (a los que fueron confinados) no son un invento rrom, son un invento no-rrom que terminó por modificar su impronta hasta el punto de crear la figura del "cacique" (el tiox, en España) inexistente hasta ahora en sus tradiciones, quien les impone una dictadura al servicio de los intereses de los no-rrom10.

En Nuevas minorías, nuevos derechos, Homi Bhabha (2013) comenta el artículo 27 del Pacto Internacional de Derechos Civiles y Políticos que ha sido el instrumento más poderoso para proteger e implementar los "derechos culturales" de las minorías. En su parte pertinente, el artículo dispone: No se negará a las personas que pertenezcan a dichas minorías el derecho que les corresponde, en común con los demás miembros de su grupo, a tener su propia vida cultural, a profesar y practicar su propia religión y a emplear su propio idioma.

(Bhabha, 2013, p. 73) Sin embargo, con el correr de los años y el surgimiento de los neofascismos, varios Estados miembro propusieron enmiendas para evitar que algunos pueblos en diáspora fueran considerados minorías. Esos estados sostuvieron que: La existencia misma de minorías no asimiladas constituye una amenaza a la unidad nacional; por tanto, las provisiones relacionadas con los derechos de las minorías no debieran aplicarse en aquellos casos que pudieran favorecer la emergencia de nuevos grupos minoritarios o frustrar el proceso de asimilación, amenazando así la unidad del Estado.

(citado en Bhabha, 2013, p. 71-3) En su pasaje cultural, en el in-between como trabajadores migrantes, como refugiados políticos, como parte de la masiva diáspora económica, de los desplazamientos culturales y sociales del mundo contemporáneo, las antiguas y las nuevas minorías en tránsito viven un presente perpetuo. Hommi Bhabha lo nombra como el "presente benjaminiano: ese momento expulsado del continuum de la historia". La mayoría de ellas no sólo deambulan sino que buscan asilo. Los rrom, por su parte, reclaman (re)conocimiento: dejar de ser simbólica y físicamente invisibles. Reclaman derecho a transitar con protección de los Estados nacionales para poder seguir vivos, porque la sedentarización los paraliza y el nomadismo es su forma de no estar afuera de este mundo.

El nomadismo en el arte

Si para Deleuze y Guattari la historia nunca ha tenido en cuenta el nomadismo (cultural y geográfico) y el libro nunca ha tenido en cuenta el afuera que carece de imagen, de significación, de subjetividad (1988, p. 28), ciertas expresiones artísticas y literarias adquieren un sentido estético y político destacado. Hay obras que se pueden pensar en relación con situaciones históricas y sociales que, de uno u otro modo, han influido, no solo en sus escenarios de producción, sino también en sus modos discursivos: en qué y cómo narran y cuál es su situación de enunciación. 
La historia política y social de los grupos minoritarios en tránsito -en este caso, de los rrom- estuvo y está marcada por una deshumanización propiciada por los Estados (con su aparato legal; con la lógica de construir identidades por exclusión) y por las comunidades donde circulan (con la conformación de otredades negativas; por su condena social). Deshumanizar significa quebrar la dignidad del ser humano, lo que facilita, como se comentó más arriba, su exterminio. Ausentes de los relatos "sobre" su cultura y "sobre" su modo de vida en tanto productores y receptores de esos relatos, los rrom fueron representados, en la literatura y las artes visuales occidentales, como personajes exóticos, estetizados, que transitaban por la vida y el mundo sin ataduras, poseedores de gran talento para el baile y el canto.

En su producción artística, el fotógrafo Josef Koudelka (nómada por elección) y el escritor Jorge Emilio Nedich (sedentario también por elección) ponen en el centro de la escena a este grupo en tránsito como topos y como mecanismo discursivo, apartándolo del margen para otorgarle visibilidad. Contemporáneos pero de puntos geográficos extremos, el "polaco" Koudelka y el "argentino" Nedich comparten un lugar de encuentro en la temática que, por ubicua, resulta universal. Comparten, también, una honda preocupación humanística subyacente en sus relatos que relatan, en definitiva, los fracasos de una de las minorías en tránsito.

\section{Nedich: "La escritura encarcela"}

Jorge Emilio Nedich (1959)11 pertenece a una familia que fue nómada hasta que él cumplió diecisiete años, por lo que no pudo escolarizarse. Fue a la escuela algunas veces pero, al poco tiempo de asistir, su familia partía del lugar y tenía que abandonar. Sin embargo, fue capaz de alfabetizarse por su cuenta. Es el primer gitano escritor en Argentina o, por lo menos, que publica, lo que rompe con una de las características esenciales de su pueblo: carecer de escritura.

Nedich, en El aliento negro de los Romaníes (2004), produce un relato sobre su infancia nómada que se aclimata, en un principio, al imago romantizado del mundo "gitano", confiando en un modo de representación realista. Este relato coincide con el de su libro de no-ficción El pueblo rebelde. Crónica de la historia gitana (2010) y con el de sus entrevistas.

En ellas comenta que ser nómada le daba un sentido de libertad que no volvió a sentir nunca más: Acampar en sitios alejados de los pueblos, debajo de los árboles, y despertar en la carpa con el canto de los pájaros era algo maravilloso. Pero después, el contacto con el mundo ya tiene otro color. El gitano más radical tiene un retraso de dos siglos.

(Zeiger, 2000) Pero en la adolescencia, al empezar el contacto con el "otro mundo", la educación sentimental se revela crudamente cuando: Empezás a advertir que el mundo va más allá de tu hábitat, y que es muy duro, que hay discriminación. Entonces uno sufre un shock y se pone a pensar. Ese es el desencanto del nomadismo: cuando vas entendiendo que estás atrasado con respecto al mundo.

(Zeiger, 2000) Para Nedich, nomadismo y oralidad articulan su sistema de subsistencia. Ser nómada sirve para no modificar las costumbres, para mantener la identidad en el circuito del día a día.

En esta fijación, se asegura que los ritos regresen eternamente. Para el rrom, dice Nedich, el presente contiene todo lo que necesita el individuo; así, el tiempo se vuelve presente constante, hasta tal punto que en ninguna de 
las lenguas rromaní existen las palabras "historia" "pasado" y "futuro", aunque hay préstamos de otros idiomas, como en el caso del subgrupo ludar12. Nomadismo y oralidad, en tanto instancias fugaces, se oponen a cualquier propuesta organizativa de largo plazo (Nedich, 2010, p. 26). La organización del clan no se construye con el recuerdo del pasado ni con la mirada en el futuro. Por ello, los reaseguros institucionales que existen en las sociedades no-rrom como la previsión social, no entran en su concepción de vida, ni por su cosmovisión ni por su funcionamiento profundamente individualista. La idea misma de aportes jubilatorios, en vistas a esperar un futuro mejor, se entiende como una actitud cobarde, propia de hombres (quienes se ocupan del sustento del clan) que no tienen confianza en sí mismos ni en su familia (Nedich, 2010).

Hasta mediados del siglo XX, el noventa por ciento de los habitantes rrom de Argentina era analfabeto. En parte era así porque se resistían -y temían- al ingreso de categorías y de valores ajenos a su cultura. Una vez que decidieron sedentarizarse, empezaron a aprender a leer y a escribir, aunque, prácticamente, no concurrían a las escuelas.

Es el caso específico de Nedich: accede a la escritura cuando se sedentariza. Es autodidacta, con una breve asistencia a la escuela primaria y ninguna a la secundaria, pero estudió en la universidad de Lomas de Zamora, gracias a la aplicación de una ley de educación especial para adultos (la Ley Nacional 26.206) sancionada en Argentina en 2006. En su papel de escritor profesional, es consciente de que ninguna de las personas de su pueblo leerá sus textos. Su madre, cuando se publicó El aliento negro de los romaníes, le pidió que a ella le diera solo la tapa porque no sabe leer (Guerriero, 1999): reclama la imagen, no las letras.

En El aliento negro de los romaníes (2004) la presencia referencial o temática es muy fuerte.

Nedich trabaja más en el tema que en el discurso y lo que escribe en código ficcional lo va a reescribir, años más tarde, en clave de crónica histórica: El pueblo rebelde (2010). Elabora un sistema fijo de referencias explícitas que funcionan tanto en un registro como en otro, en el borde de los géneros. En sintonía con la línea de literaturizar la vida de los "gitanos" que se desarrolló furentemente desde el siglo XVII y que tuvo su auge en la literatura del siglo XIX de Europa y Norteamérica13, se advierte, en su novela, una romantización de la vida de su pueblo de origen. A partir del gran topos "gitano" los significados se concentran en un grupo de subtemas, especialmente los atinentes a la vida de una familia tipo, según la tradición: el matrimonio de Petre y Maida, con sus hijos Carlo, Penca, Mina y Andryé la intervención de los padres del marido, Ipe y Totole.

Esta novela -más reproductio que inventio- despliega todas las costumbres, los mitos y las creencias: los matrimonios arreglados, los nacimientos, la sexualidad, el erotismo, la muerte, los oficios, la ausencia de escritura, los robos y engaños a los que recurrían para sobrevivir, los prejuicios sociales, las supersticiones, la persecución por parte de los aparatos del estado, la costumbre de contar pobiaste (cuentos) por las noches, la intervención de las leyendas sobre su origen, las relaciones conflictivas entre los distintos grupos rrom, la ruptura de algunas tradiciones, el desarrollo de la vida en el presente perpetuo.

En la búsqueda de la escritura como defensa posible, el primer escritor profesional gitano de Argentina -y, hasta donde se conoce, de América Latina-, propone, en su ficción, suturar la ancestral brecha entre conservar la identidad étnica, su esencia rrom o convertirse en no-gitanos, bajo el paraguas de la asimilación. La novela se cierra con este párrafo: Mientras el que parecía llegado del cielo abrazaba a Maida y le hablaba bajito tratando de convencerla de lo venturosa que sería la vida si todos partían. Le aseguró que Dios había dispuesto todo. Ya 
tenían las hijas casadas, un animal bailarín, el dinero obtenido por la dote y el circo que los aguardaba para recorrer el mundo. Maida escuchó obediente lo propuesto por el Arcángel y se alegró cuanto vio que a Carlo la idea le agradaba. Petre, en cambio, le dijo a su hijo en un tono que no admitía contradicción: que podía irse con el circo porque él y Maida se quedarían en el pueblo. Repetía orgulloso para que lo escuchara el que parecía llegado del cielo que se acercaba la hora de los grandes cambios. Había que cambiar la mala fama que perseguía a los romaníes.

(Nedich, 2005, pp. 214-15)

Koudelka: "Miro y todo me influencia"

A Jose Koudelka (1938)14 se lo conoce como el "fotógrafo nómada" o como el "fotógrafo apátrida" porque pasó casi toda su vida viajando. Se sabe muy poco de él, excepto por algunas entrevistas que ha ofrecido cuando se realiza alguna exhibición de su trabajo.

Realizó su proyecto creativo más extenso entre los años 1962 y 1968 cuando se fue a vivir a campamentos rrom -instalados en la región este de Eslovaquia, en Rumania y en Irlanda- para fotografiarlos. El producto del trabajo de esos años es la serie Gypsies, que se publicó en 1975 y que se expuso en los museos de arte más prestigiosos y exclusivos de las metrópolis de Europa y Estados Unidos.

En el año 1970, Koudelka fue declarado oficialmente apátrida, dos años después de que los países del pacto de Varsovia invadieran la ex Checoslovaquia. Había tomado fotografías del avance de los tanques y las tropas sobre Praga, donde vivía. Las fotografías salieron clandestinamente del país, pero este hecho le significó un exilio forzoso que duró más de veinte años y que lo empujó a viajar sin tener asiento fijo,15 aunque estableció una suerte de sede en París.

Con motivo de una de sus muestras fotográficas, se publicó en el New York Times una entrevista de James Estrin, "A Restless Eye" (20 de noviembre de 2013)16, en la cual comenta que muchas personas sienten curiosidad por su nacionalidad y le preguntan si es checo o francés, a lo que responde: "No sé qué soy, las personas que me miran podrán decir quién soy. Soy el producto de todo este viaje ininterrumpido, pero sé de dónde vengo [...] He viajado durante cuarenta años y nunca estoy en un país más de tres meses, porque me interesa ver, y si estoy más tiempo me vuelvo ciego". Y agrega: "Solamente viajo. Miro y todo me influencia" (2013).

No permanece mucho tiempo en un solo lugar y en sus viajes solamente lleva lo que necesita: dos camisetas (que "me duran tres años"), sus cámaras, película, un par de anteojos extra y algo de dinero. Por su estilo austero al extremo, cuando convivía con los rrom, consideraban que vivía aún en peores condiciones que ellos porque, por las noches, cada uno se iba a sus carromatos y él era quien dormía a la intemperie (O’Hagan, 2008). La misma percepción tenían los niños gitanos en Gran Bretaña, quienes siempre le hacían dos preguntas: “¿duermes vestido? y “¿cuándo fue la última vez que viste a tu gente?”. Koudelka dice que, aun siendo nómadas, los rrom tenían el hábito de volver a los mismos lugares cada año para reencontrarse con su gente, reforzar los vínculos y enterarse de lo sucedido en su ausencia, y, como él no podía regresar a ningún sitio, les generaba sentimientos de conmiseración (O’Hagan, 2008). 
Para Koudelka, la inmovilidad significa ceguera. Cuando se vive en un lugar, afirma, es muy fácil dejar de ver algo importante, se puede obviar lo trascendente, sobre todo, si la intención es ignorarlo. Ilustra con el ejemplo de una amiga suya, eslovaca, que vivía cerca de los campamentos rrom y que cuando vio el libro Gypsies le dijo "que nunca había notado que los gitanos eran tan guapos. Esa es la cosa: todos miramos a nuestro alrededor, pero no todos vemos" (Minera, 2003).

Cada vez que se muda ve algo diferente, siente que renace porque en su proyecto creador, el hecho de fotografiar tiene que ser siempre distinto. Considera sus cuarenta años de errancia como un aprendizaje y un enriquecimiento personal. Asegura que de su estancia en los campamentos rrom aprendió que nada es permanente y que el futuro nunca debe ser en una preocupación. También, que lo único que cada ser humano posee es tiempo (Estrin, 2013). En este sentido, comenta en una entrevista que: El escritor Bruce Chatwin en un libro que se titula The Songlines, sobre un pueblo aborigen de Australia dice que han podido sobrevivir en un medio tan hostil gracias a unas pocas reglas: la primera es que permanecer en un lugar significa suicidio: la segunda es que tu lugar es donde no te preguntas nada sobre ti mismo; la tercera es que tu lugar es de donde te vas y que en un período de crisis debes elaborar una vía de escape y la cuarta es tener buenas relaciones con tus vecinos.

(Estrin, 2013) Su trabajo consistió durante mucho tiempo en fotografiar personas sin raíces: la serie Exiles (1988) es sobre gente que tuvo que dejar su lugar y Gypsies es sobre personas que no tienen lugar o que su tierra será el próximo lugar al que lleguen (Estrin, 2013). La compilación de Gypsies fue un proyecto que, cuando lo inició, no tenía objetivos claros, pero sí sabía que estaba construyendo algo y que debía "abarcarlo todo". Dijo al respecto: "El gitano en la Checoslovaquia de los años 60 es el otro por excelencia, el rechazado, el no aceptado, el sospechoso, el no asimilado, el supuesto mentiroso, el ladrón, todo al mismo tiempo" (Colorado, 2012).

El arte, para Koudelka, no puede cambiar el mundo. Bajo esta concepción, su serie Gypsies no fue hecha con la intención ulterior de "salvarlos". Al paso de los años ha manifestado que su trabajo tampoco sirvió para ayudarlos $\mathrm{y}$, sin embargo, los rrom han sabido resistir todo régimen económico y social. Agrega que "toda iniciativa por apoyarlos o destruirlos ha fracasado. Los gitanos parecen inmunes a todo lo que no sean ellos mismos" (Colorado, 2012). Aún así, en cada una de sus fotografías hay un completo sistema de información.

Por su empatía con el sujeto, se advierte que no se trata solamente del lenguaje de las fotos, sino de la traducción visual de lo que ellas "relatan".

El caso que aquí se indaga, la fotografía del hombre que camina hacia la cámara, esposado, (tomada en Bardejov, 1967), además de funcionar como un registro del pasado, del recorte de tiempo que ha sido "real", deviene una manera de interpretar el presente (Sontag, 2006, p. 232).

La imagen fotográfica tiene el poder de evocar el relato invisible en la foto que lo ha producido, y que solo la foto (esta foto) puede hacer visible, es decir, puede hacerlo hablar. Se trata de reponer lo que está ausente en el nivel de superficie por el mandato específico que tiene la imagen, el mandato de visualizar lo existente, el instante "real". La fotografía aísla la apariencia de un instante fotografiado que solo adquiere sentido en tanto el decodificador u observador pueda leer una duración extendida más allá de ella. Por ello, cuando se le da significado a una fotografía se le aporta pasado y futuro (Berger y Mohr, 1995, p. 66). 
Como la descripción literal de una foto es imposible (Barthes, 1986, p. 14), entonces se trata de reponer sentidos ausentes en la imagen pero presentes en los códigos culturales de los receptores, en esa reserva que va a permitir otorgarle significado.

En la fotografía (Imagen 1) se ve al hombre joven que camina hacia la cámara con desconcierto, el cabello desmarañado, la mirada casi de sorpresa, profundamente triste. Lleva un saco que no coincide con él, con el escenario; es un saco grande que aumenta lo absurdo de la situación17.

Según Susan Sontag, el encuadre enfatiza, afirma, personaliza la situación general (2006, p. 229); aquí, la elección del gran angular sumando a la angulación en picado de la cámara generan una figura del hombre más ancha arriba, que se va angostando hacia abajo.

La imagen del joven termina constreñida por las esposas dándole la forma de un ataúd.

Junto a esto se ve, en el camino de barro, la huella del camión que "sale" de su cuello y va dibujando la soga de la horca, prefigurando su castigo fatal (se supo que el hombre fotografiado estaba acusado de homicidio).

Se ve el "imperio" de la ley en la minimalidad de la autoridad presente, tan solo la poca que se necesita para tanto exceso de castigo, y que contrasta con la desproporcionada presencia, en número, de lo castigado, simbolizados en la línea patética de personas que miran hacia el hombre expulsado. Si la fotografía pide una interpretación y las palabras se la proveen (Berger y Mohr, 1995, p. 92) es posible (re)poner todos y cada uno de los temas que han caracterizado el pasado y el presente de la vida nómada de los rrom: la pobreza, la expulsión, los aparatos del estado que ejercen su autoridad (policía), la cárcel (esposas), la muerte (el castigo), en fin, el estado general de inermidad.

Lo que Barthes (1986) llamó la connotación "ética o ideológica" de las fotografías introduce valores o razones en la lectura de la imagen; y lo que llamó lectura "política" es la que permite todos los lenguajes. Leer políticamente esta fotografía (a pesar de su autor) permite condensar en ese recorte de presente, en esa elección del fotógrafo de lo que ha de ser fotografiado, la evidencia de que así sucedieron las cosas.

Reconocerlo, y entender el lugar intersticial (Bhabha) que ocupan en la literatura (Nedich) y en el arte (Koudelka) estos sujetos nómadas, no solo es ponerlos en superficie, sino también abrir(nos) la posibilidad de empezar a imaginar comunidades en las que se atiendan las necesidades y los derechos de las minorías en tránsito.

Notas

1. La grafía de doble -r en las palabras rrom, rroma, rromaní corresponde con más exactitud a la pronunciación que tiene en muchos dialectos de esa lengua. En el caso de algunas de ellas, el uso de la doble -r evita posibles malentendidos y confusión con palabras que suenan parecidas, tales como Rumania y Roma. Dentro de las comunidades y entre los que hablan la lengua, también se utiliza comúnmente romanes; literalmente significa "de la manerar rom". Se puede consultar, entre otras fuentes a: http://www.translationromani.net. Se pronuncia como el fonema /G/.

2. A fines del siglo XVIII, estudios lingüísticos confirmaron que, por su gramática y por su vocabulario, la lengua rromaní (o rrom) se aproxima al sánscrito y a algunos idiomas vivos como el cachemir, el hindi, el guajarati, el 
marathi, el urdu, el bengalés, el singalés o el nepalés (de Vaux de Foletier, 1984, pág. 6). Al establecer su derivación del indo-iranio (Diccionario Etimológico indo-europeo de la lengua española, 1997) se pudo afirmar científicamente el origen indio de estos grupos nómadas.

\section{Afirma Amadou-Mahtar M'Bow que este pueblo ha adoptado el nombre de rrom (rromíes, rromaníes)} aceptado por las Naciones Unidas, y que ha rechazado los términos de gitanos, cíngaros y otros que les fueron impuestos desde afuera (1984, pág. 5). También, François de Vaux de Foletier dice que en Grecia se los llamaba atkinganos o atsinganos, nombre de una "secta" de músicos y adivinos (pág. 6). También, que en una de las escalas principales de los rrom, en su ruta de Venecia a Jaffa, la ciudad de Modón, fueron descubiertos por los viajeros occidentales y dijeron que eran "negros como los etíopes". A ese lugar geográfico se le llamaba "el Egipto Menor", probablemente porque era un espacio fértil en medio de una región muy árida, como lo era el delta del Nilo. Por esto, a los rrom de Europa se les llamó egipcianos, gitanos o gypsies (1984, pág. 6).

4. Esto es tan claro y tan actual, que en la Conferencia Ciudadana contra el Racismo, de Naciones Unidas, año 2000, en su "Declaración del pueblo Rrom a los pueblos, gobiernos y estados de Las Américas", manifiestan que: "nuestro pueblo no tiene dentro de su opción civilizatoria la conformación de un proyecto estatal propio [...] nuestro interés y voluntad de aportar, desde nuestra situación de pueblo victimizado históricamente por las lacras del racismo, la discriminación, la xenofobia y la intolerancia, desde nuestra cosmovisión y tradición cultural específicas, lo mismo que desde nuestra vida itinerante y nómada [...]" (3-4 de diciembre de 2001, Organizaciones Rrom de las Américas).

5. Hay un desarrollo previo de estos conceptos en Laura Ruiz: "La palabra nómada. Representación y exterminio en la Patagonia sur en Fuegia y Pequeño Pie de Piedra".

6. No sólo en los tempranos siglos XV, XVI y XVII este relato desarrolló un poderoso simbolismo alrededor a los rrom: en el juicio de Nürnberg, el oficial SS Otto Ohlendorf justificó la matanza de rrom apoyándose en la descripción literaria que Friedrich Schiller hace de La Guerra de los Treinta Años, en una manera muy similar a la historia de los clavos de la crucifixión de Cristo. Todavía en 1990 la policía de Estados Unidos invocaba esta leyenda para justificar las políticas de atropello contra los rrom (Trumpener, 1992, págs. 848-49).

7. Por ejemplo, los diarios de Bucarest, en 1845, publicaron anuncios relativos a la venta de doscientas familias pertenecientes a un noble rumano y, en 1851, un diario de Moldavia publicó los nombres y la descripción de trescientos cuarenta y nueve gitanos (hombres, mujeres y niños/as) que pertenecían al fallecido ministro Alecu Sturdza y se ponían a la venta junto con el mobiliario (Taikon Janush, 1984, pág. 19).

8. Ver sobre este tema y sobre la documentación al respecto: "Los Rrom en las Américas" de Jorge Bernal en Patrimonio Cultural Gitano (2005). Buenos Aires: Preservación del patrimonio cultural Buenos Aires (pp. 95-148).

9. Durante la década de 1990, un número importante de rrom de Rumania llegaron a Argentina. Reclamaron que habían sido marginalizados y humillados en Rumania y durante los años más conflictivos, las dificultades se habían extendido a todos los países de Europa oriental. Sin ningún oficio, terminaron mendigando en las calles. Se identificaban como rumanos para evitar problemas cotidianos de discriminación. En una ocasión, representantes de los medios de comunicación visitaron la embajada rumana en Buenos Aries para obtener 
información. La respuesta de la embajada fue que "esa gente no eran rumanos, que eran gitanos" (Unión Romaní).

10. Zeljko Jovanovic, de la fundación Open Society de Budapest, cuenta que en un pequeño pueblo de Hungría el $70 \%$ de la población es rrom pero gobierna la extrema derecha: "los votantes gitanos son más vulnerables a la venta de votos a cambio de dinero, comida, distribución de subsidios o empleos públicos", de lo que se ocupa el cacique, único vínculo entre los rrom y los no-rrom.

11. Jorge Emilio Nedich nació en Sarandí, provincia de Buenos Aires en 1959. Publicó Gitanos, para su bien o su mal (1944), Ursari (1997) ambas por Torres Agüero Editor, Leyenda gitana (2000, Editorial Planeta), El Pepe Firmenich (2003, Ediciones B), El aliento negro de los romaníes (2005, Planeta) y El pueblo rebelde. Crónica de la historia gitana (2010, Ediciones B.) y El alma de los parias (2014, De la flor).

12. Ahora hay prestamos, en el caso de los ludar están los vocablos historie, futuru, pasadu (Nedich, 2010, pág. 26).

13. Ver el detallado artículo de Katie Trumpener sobre este tema.

14. Nació en Boskovice, Moravia, ex Checoslovaquia, en 1938. Estudió ingeniería aeronáutica en la universidad Técnica de Praga y trabajó en la profesión durante siete años hasta que se dedicó enteramente a la fotografía, a partir de 1967.

15. Sobre el exilio ha dicho en varias ocasiones que incorporó la experiencia como aprendizaje. En entrevista con María Minera dice: “¿sabes cuál es la cosa más importante que puedes aprender de la fotografía? Que del negativo se hace el positivo. Y hay que trasladar eso a la vida y afrontarla así. [...] Para mí, toda la vida es un regalo y el exilio lo fue también: me impulsó a cambiar. Si yo hubiera seguido en Checoslovaquia, probablemente habría hecho algunas fotografías más de gitanos y punto. El exilio me permitió reinventar el sentido de mi vida y reaccionar a cosas nuevas. Además, me dio un segundo regalo: la posibilidad de regresar y ver todo lo que conocía de otra manera".

16. Se puede traducir como "Un ojo que no descansa".

17. En "El traje y la fotografía", John Berger dice que el traje se desarrolló en Europa, en el siglo XIX, como vestimenta de la clase dirigente y que "fue el primer vestido de la clase alta que idealizaría puramente el poder sedentario. [...] Esencialmente, el traje fue hecho para la gestualidad que acompaña a la charla y al pensamiento abstracto" (p. 51).

Bibliografía

Anderson, B. (1993). Comunidades imaginadas. México: Fondo de Cultura Económica.

Arditi, B. (2000). El reverso de la diferencia. Identidad y política. Caracas: Nueva sociedad.

Barhtes, R. (1986). El mensaje fotográfico. En Lo obvio y lo obtuso (pp. 11-28). Barcelona: Paidós. 
Berger, J. (1998). El traje y la fotografía. En Mirar. Buenos Aires: Ediciones de la Flor.

Berger, J., y Mohr, J. (1995). Appearances. En J. Berger, y J. Mohr, Ways of Reading (pp. 81- 130). UK: Vintage Books.

Bernal, J. (2005). Los Rrom en las Américas. En Patrimonio Cultural Gitano (pp. 95-148). Buenos Aires: Preservación del patrimonio cultual Buenos Aires.

Bernal, J. (28 de junio de 2014). AICRA Asociación identidad Cultural Romani en Argentina. Obtenido de http://www.aicra.com.ar Bhabha, H. (2013). Nuevas minorías, nuevos derechos. Buenos Aires: Siglo XXI.

Charlemagne, J. (1984). Las nuevas generaciones: vivir el pasado en presente. Correo de la UNESCO, 15-16.

Colorado, O. (17 de junio de 2012). oscarenfotos.com. Recuperado el 28 de junio de 2014, de http://www.oscarenfotos.com/2012/6/17/josef-koudelka-el-nomada de Vaux de Foletier, F. (1984). De los países del Indo al mundo occidental. Correo de la UNESCO, 5-7.

Deleuze, Gilles y Guattari, Félix. (1988). Mil Mesetas. Capitalismo y esquizofrenia. Madrid: Pre-Textos.

Denson, R. (2000). Un perpetuo regreso al inicio. El nomadismo en la recepción crítica del arte. En B. Arditi, El reverso de la diferencia (pp. 47-54). Caracas: Nueva Sociedad.

Diccionario Etimológico indo-europeo de la lengua española. (1997). Madrid: Alianza. Estrin, J. (20 de noviembre de 2013). The Restless Eye. New York Times.

Feierstein, D. (2000). Seis estudios sobre genocidio. Análisis de las relaciones sociales: otredad, exclusión y exterminio. Buenos Aires: Eudeba.

Feierstein, D. (2005). Modos de construcción de identidad en los Estados-Nación modernos. El caso argentino. En Patrimonio Cultural Gitano (pp. 24-46). Buenos Aires: Preservación del patrimonio cultural Buenos Aires.

Feierstein, D. (2007). El genocidio como práctica social. Entre el nazismo y la experiencia argentina. Buenos Aires: Fondo de Cultura Económica.

Grande, F. (1984). El cante flamenco o la sangre en la boca. Correo de la UNESCO, 28-31.

Guerriero, L. (19 de septiembre de 1999). Jorge Nedich: gitano y novelista. Recuperado el 30 de noviembre de 2014, de http://www.lanacion.com.ar/211634-jorge-nedich-brgitano-y-novelista Guy, W. (1975). Gypsies. New York: Aperture Foundation Inc.

M’Bow, A.-M. (1984). Originalidad y Universalidad del pueblo gitano. Correo de la UNESCO, 4.

Minera, M. (20 de noviembre de 2003). Entrevista con Josef Koudelka. Recuperado el 28 de noviembre de 2014, de Letras Libres: http://www.letraslibres.com/ revista/artes-y-medios/entrevista-con-josef-koudelka Nedich, J. E. (2005). El aliento negro de los romaníes. Buenos Aires: Planeta. 
Nedich, J. E. (2010). El pueblo rebelde. Crónica de la historia gitana. Buenos Aires: Vergara.

Novitch, M. (1984). El exterminio planificado por los nazis. Correo de la UNESCO, 23-25.

O'Hagan, S. (24 de agosto de 2008). 40 years on: the exiles comes home to Prague. Recuperado el 17 de junio de 20014, de The Guardian: http://www.theguardian.com/artanddesign/2008/aug/24/photography Ruiz, L. (2012). La palabra nómada. Representación y exterminio en la Patagonia Sur en Fuegia y Pequeño Pie de Pidra. En M. A. Fanese, Representaciones y sujet*s. Discursos sociales y expresiones estéticas (pp. 113-136). Córdoba: Alción.

San Román, T. (1985). ¿Hay un lugar para el pueblo gitano? En M. Izard, Marginados, fronterizos, rebledes y oprimidos Tomo I (pp. 139-157). Barcelona: del Serbal.

Sontag, S. (2006). Sobre la fotografía. México DF: Alfaguara.

Soravia, G. (1984). La lengua, rastro de una larga peregrinación. Correo de la UNESCO, 19-23. Taikon Janush, R. (1984). El entorno y la tradición en la estructura familiar. Correo de la UNESCO, 19-20.

Trumpener, K. (1992). The Time of the Gypsies: "A Peolple without History" in the Narratives of the West. Critical Inquiry, 18(4), 843-884.

Unión Romaní. (s.f.). Recuperado el 24 de marzo de 2014, de http://www.unionromani.org/tchatchi/thcatchi48.htm Zeiger, C. (23 de abril de 2000). Papel romaní: Jorge Emilio Nedich, gitano y escritor. Recuperado el 8 de marzo de 2014, de Radar: www.pagina12.com.ar/2000/suple/radar/00-04/00-04-23/nota2.htm

Abstract:

The purpose of this paper is to examine how words and images tell and represent characteristics of the Rrom people (commonly known as "gypsies") such as nomadism, persecution, marginalization and their own obstinacy to live in an endless present time. The analysis is focused on the novel El aliento negro de los romaníes, on the non-fiction text El pueblo rebelde. Crónica de la historia gitana both by Rrom-Argentine writer Jorge Nedich, and on a photograph by Czech-French photographer Josef Koudelka (collected in Gypsies). Therefore, the article explores the aporia of the symbolic representation of a people that, in spite of being illiterate, have been shown in art and literature as an exotic, stereotyped other, by the condescending point of view of nationalist illustrated hegemonies.

Key words:

nomadism - otherness - identity - literature - photography - gypsies.

Resumo:

Este trabalho pretende examinar os modos de contar ou de representar nos quais a palavra e a imagem põe em cena características do transcorrer no mundo do povo Rrrom (cigano): nomadismo, perseguição, marginalização 
e a própria obstinação por permanecer em um presente perpétuo. Tendo como foco o romance El aliento negro de los romaníes, o texto El pueblo rebelde. Crónica de la historia gitana do escritor rrom-argentino Jorge Nedich, e a fotografia do tcheco-francês Josef Koudelka (em Gypsies), o artigo explora a aporia de apresentar simbolicamente um povo que, apesar de ágrafo, transitou a literatura e a arte como um outro exótico, estetizado ou estereotipado pelo discurso condescendente das ilustradas hegemonias nacionalistas.

Palavras chave:

nomadismo - alteridade - identidade - literatura - fotografia - ciganos.

Bronce y sueños, los gitanos. Nomadismo, identidades por exclusión y otredad negativa en Jorge Nedich y Josef Koudelka fue publicado de la página 123 a página141 en Cuadernos del Centro de Estudios de Diseño y Comunicación № 61 